\title{
Fine Size Cobalt Oxide Powders Prepared by Spray Pyrolysis Using Two Types of Spray Generators
}

\author{
Seo Hee JU, Seung Kwon HONG, Hee Chan JANG and Yun Chan KANG ${ }^{\dagger}$ \\ Department of Chemical Engineering, Konkuk University, 1, Hwayang-dong, Gwangjin-gu, Seoul 143-701, Korea
}

\begin{abstract}
Spherical shape cobalt oxide powders with fine size were directly prepared by spray pyrolysis using a filter expansion aerosol generator (FEAG). These cobalt oxide powders were then compared with the powders prepared by ultrasonic spray pyrolysis. The cobalt oxide powders prepared using a FEAG are finer and have more narrow size distribution and filled morphologies than those prepared by ultrasonic spray pyrolysis. The mean sizes of the cobalt oxide powders prepared using a FEAG increased from 230 to $860 \mathrm{~nm}$ when the concentration of the spray solution was increased from 0.01 to $2 \mathrm{M}$.

[Received April 17, 2007; Accepted June 14, 2007]
\end{abstract}

Key-words : Spray pyrolysis, Cobalt oxide, Ultrasonic, Black matrix

1. Introduction

Tricobalt tetraoxide $\left(\mathrm{Co}_{3} \mathrm{O}_{4}\right)$ powder is believed to be a promising material for gas sensors, catalysts, lithium secondary batteries, etc. ${ }^{1)-5)}$ Especially, fine cobalt oxide powders are developed as black matrix materials for flat panel displays [black matrix enhances the contrast of flat panel displays like the plasma display panel (PDP) ]. Fine cobalt oxide powders are synthesized through various aqueous-solution-based methods, such as hydrothermal synthesis, precipitation, and the sol-gel method. ${ }^{6)-11)}$

Spray pyrolysis is one of the more promising processes for the preparation of improved ceramic and metal powders. ${ }^{12)-16)}$ In spray pyrolysis, one powder is formed from one droplet at mild preparation conditions. Therefore, the mean size and size distribution of the powders prepared through spray pyrolysis at mild preparation conditions are strongly affected by the spray generator used. In spray pyrolysis, an ultrasonic spray generator is used for the preparation of submicron ceramic and metal powders because the ultrasonic spray generator can generate relatively homogeneous droplets several microns in size. However, below-500-nm fine ceramic powders could not be prepared through spray pyrolysis, using an ultrasonic spray generator, due to the high concentration of the spray solution used.

Kang and Park proposed the use of a new spray generator, the filter expansion aerosol generator (FEAG), in the preparation of powders and thin films under reduced pressure. ${ }^{16)}$ In this work, fine, spherical cobalt oxide powders were directly prepared through spray pyrolysis, using a FEAG. The mean sizes of the cobalt oxide powders were controlled by varying the concentrations of the spray solution. The cobalt oxide powders prepared using the FEAG were then compared with the powders prepared using the ultrasonic spray generator.

\section{Experiments}

The schematic diagram of the FEAG process used in this study was shown in Fig. 1. The FEAG process consists of a porous glass filter, an ultrasonic spray generator, a vacuum pump and a bag filter. ${ }^{17)}$ In the FEAG process, spray solution was supplied through an ultrasonic spray generator using carrier gas on to a glass filter surface where it forms a thin liquid film. This liquid film is passed through the filter pores by the carrier gas and expanded into a low pressure chamber. In the ultrasonic spray pyrolysis process, droplets formed by

\footnotetext{
† Corresponding author; E-mail address: yckang@konkuk.ac.kr
}

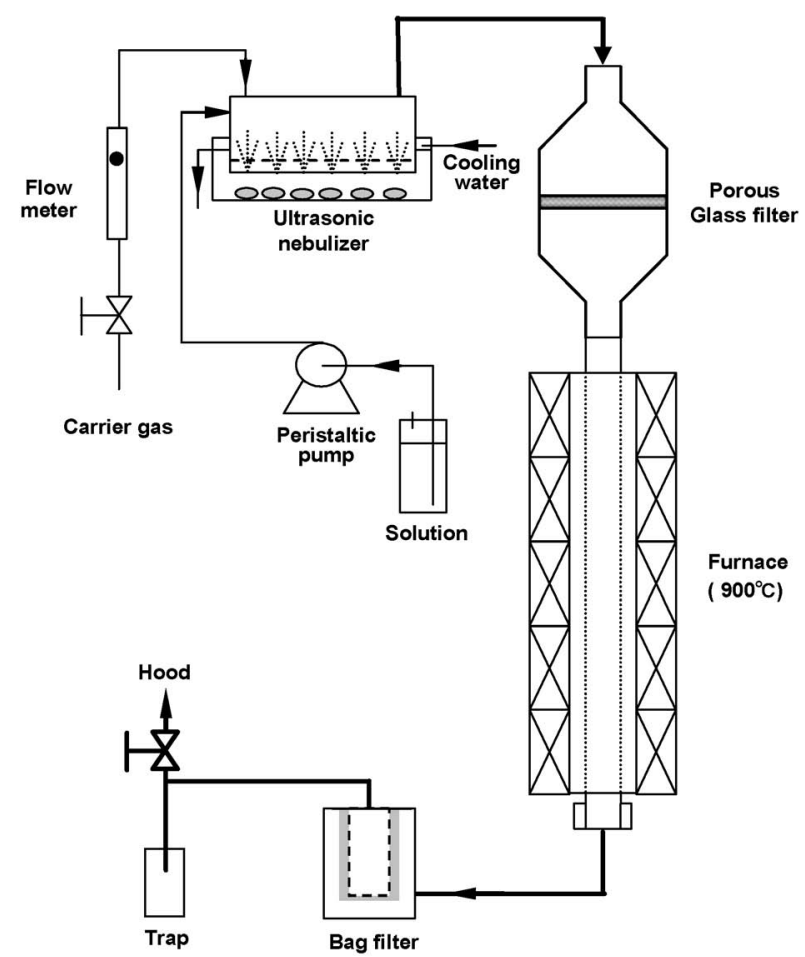

Fig. 1. Schematic diagram of the FEAG process.

ultrasonic spray generator were directly supplied into the hot wall reactor. The length and diameter of the quartz reactor were 1,200 and $50 \mathrm{~mm}$, respectively. The reactor temperature was fixed at $900^{\circ} \mathrm{C}$. The concentrations of cobalt nitrate were changed from 0.01 to $2 \mathrm{M}$.

The crystal structures of the cobalt oxide powders were investigated using X-ray diffractometry (XRD, RIGAKU, DMAX-33). The morphological characteristics of the powders were investigated using scanning electron microscopy (SEM, JEOL, JSM 6060).

\section{Results and discussions}

The crystal structures of the powders prepared with the use of a FEAG and of an ultrasonic spray generator, respectively, were investigated, and the results of the investigation are shown in Fig. 2. The powders had crystal $\mathrm{Co}_{3} \mathrm{O}_{4}$ structures 
regardless of the spray generator that was used in preparing them. The cobalt nitrate precursors were converted to $\mathrm{Co}_{3} \mathrm{O}_{4}$

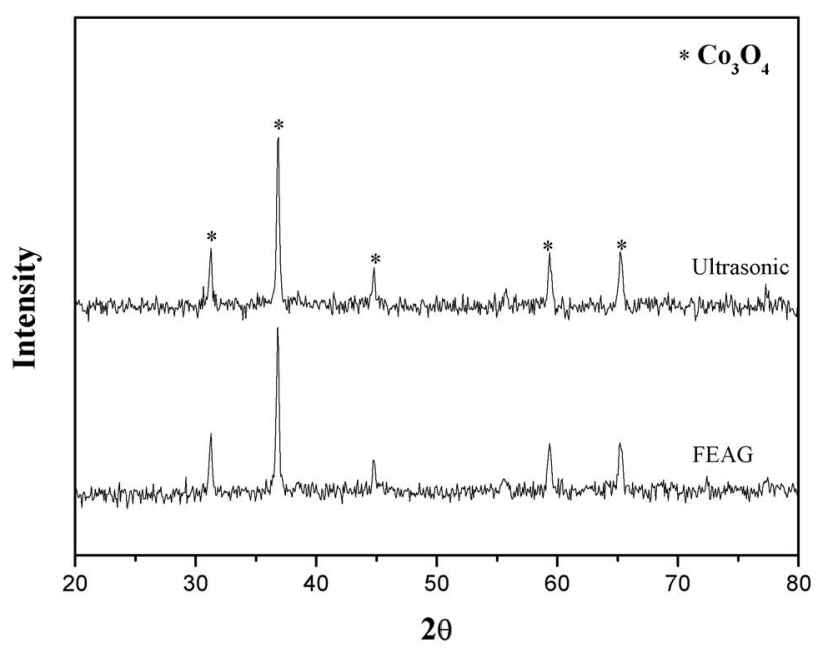

Fig. 2. XRD spectra of cobalt oxide powders. powders in spite of the short residence times of the powders inside the hot wall reactor.

Figure 3 shows SEM photographs of the cobalt oxide powders prepared using a FEAG, at various concentrations of the spray solution used. The cobalt oxide powders had a spherical shape and non-aggregation characteristics regardless of the spray solution concentration. In addition, their mean size increased as the concentration of the spray solution increased. In particular, the mean size of the cobalt oxide powders increased from 230 to $860 \mathrm{~nm}$ when the concentration of the spray solution was increased from 0.01 to $2 \mathrm{M}$. The characteristics of the cobalt oxide powders were also affected by the concentration of the spray solution. In particular, the powders prepared from spray solutions with concentrations below $0.3 \mathrm{M}$ had dense structures and narrow size distributions. On the other hand, the powders prepared from spray solutions with concentrations above $0.7 \mathrm{M}$ had hollow morphologies and broad size distributions.

In this work, one cobalt oxide powder was formed from one droplet. Therefore, the size distributions of the cobalt oxide powders were affected by the characteristics of the droplets that were formed by the FEAG. When the FEAG was used, the characteristics of the droplets changed according to the

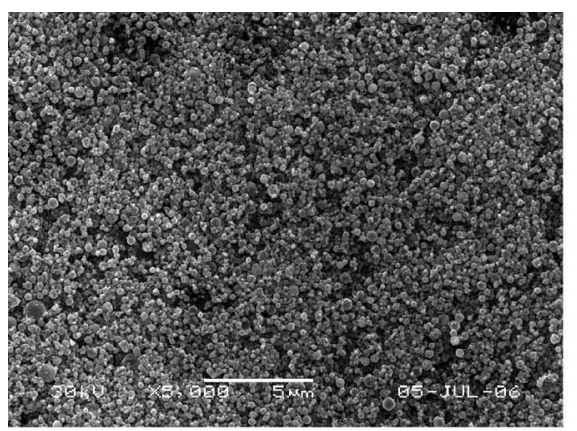

(a) $0.01 \mathrm{M}$

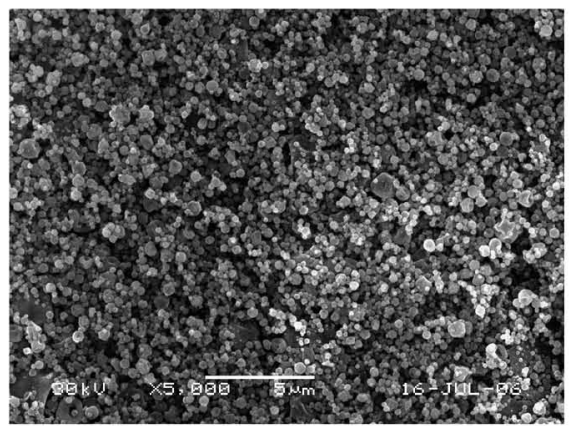

(d) $0.3 \mathrm{M}$

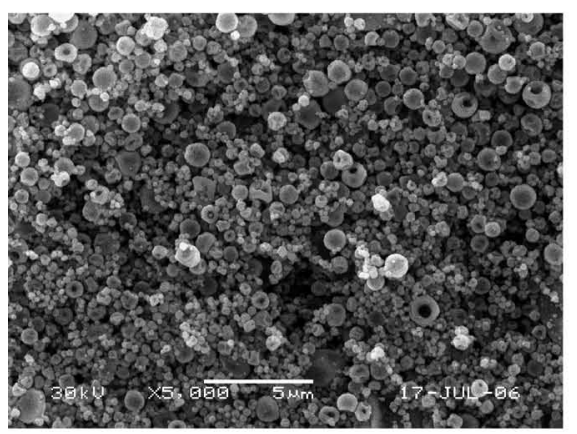

(g) $2 \mathrm{M}$

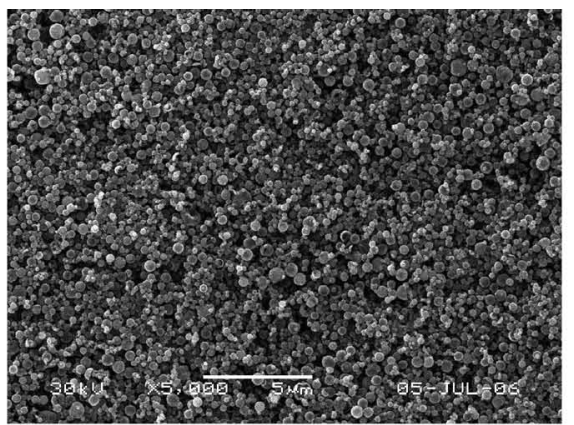

(b) $0.05 \mathrm{M}$

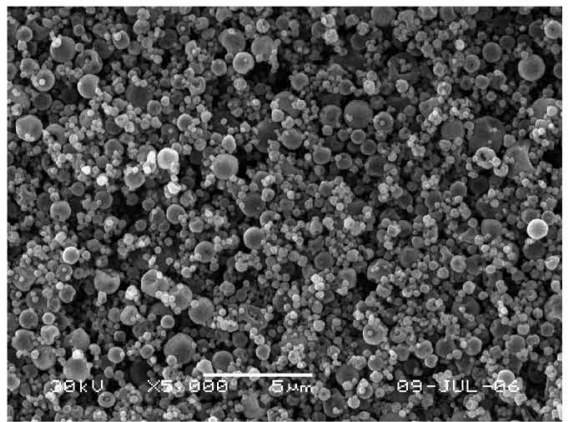

(e) $0.7 \mathrm{M}$

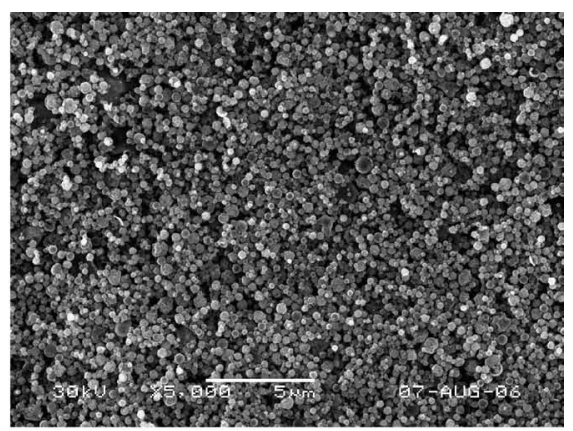

(c) $0.1 \mathrm{M}$

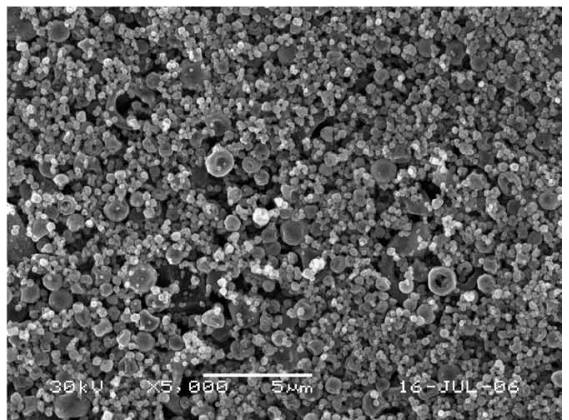

(f) $1 \mathrm{M}$

Fig. 3. SEM photographs of cobalt oxide powders prepared by the FEAG process. 


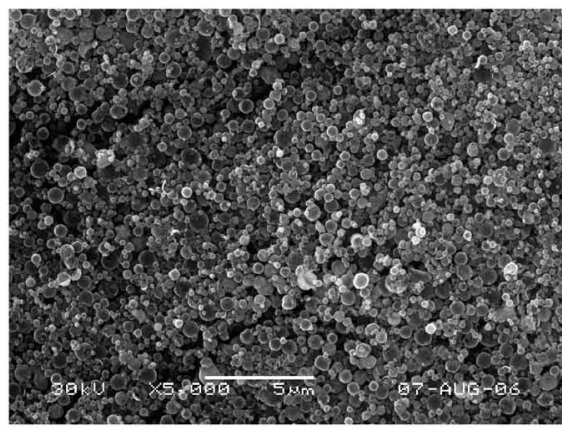

(a) $0.01 \mathrm{M}$

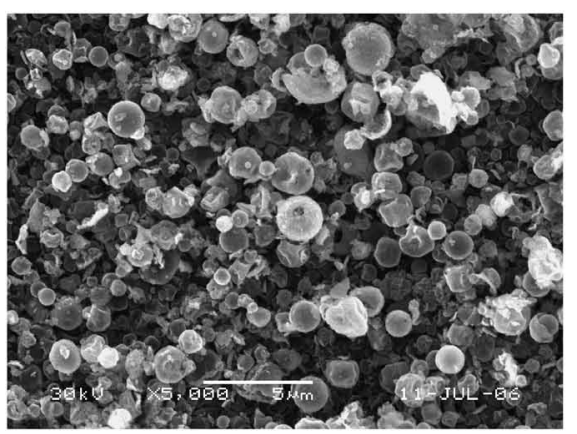

(d) $0.3 \mathrm{M}$

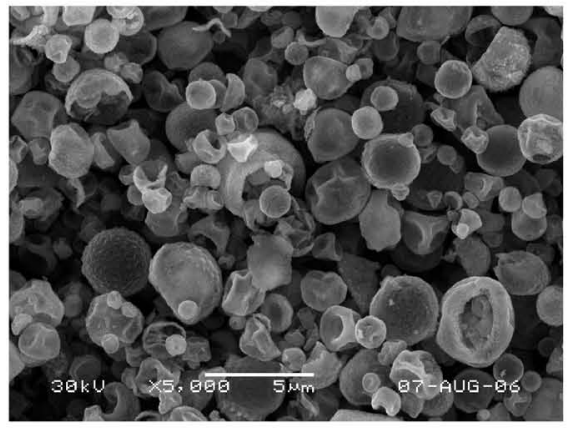

(g) $2 \mathrm{M}$

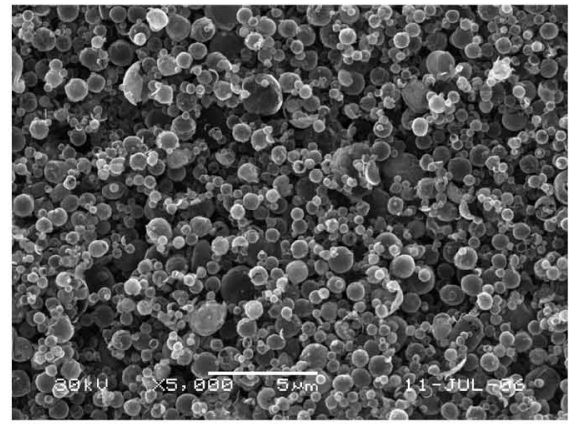

(b) $0.05 \mathrm{M}$

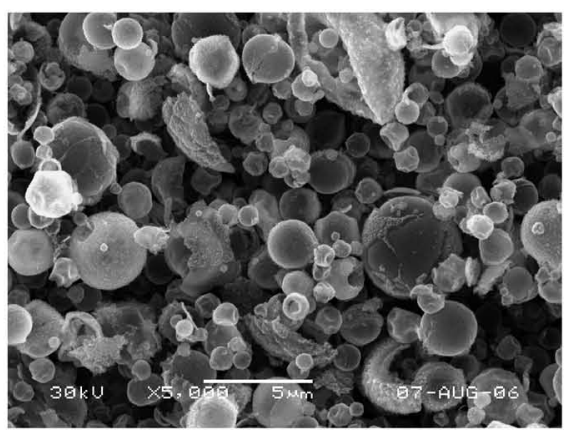

(e) $0.7 \mathrm{M}$

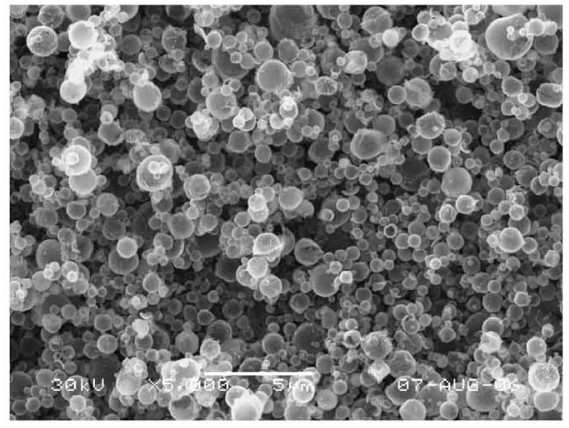

(c) $0.1 \mathrm{M}$

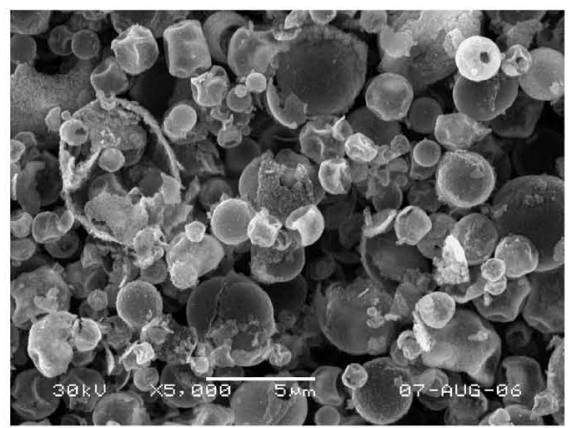

(f) $1 \mathrm{M}$

Fig. 4. SEM photographs of cobalt oxide powders prepared by the ultrasonic spray pyrolysis process.

type of spray solution used. The droplets that were formed from spray solutions with high concentrations had a broader size distribution than those that were formed from spray solutions with low concentrations. The hollow morphologies of the powders obtained from spray solutions with high concentrations also affected the powders' size distribution.

Figure 4 shows SEM photographs of the cobalt oxide powders prepared through ultrasonic spray pyrolysis. The cobalt oxide powders obtained from spray solutions with concentrations below $0.1 \mathrm{M}$ had a spherical shape and regular morphologies. On the other hand, the powders prepared from spray solutions with concentrations above $0.3 \mathrm{M}$ had hollow and fractured morphologies.

In Figs. 3 and 4, the cobalt oxide powders prepared using the FEAG were finer and had more regular morphologies than those prepared using an ultrasonic spray generator. The cobalt oxide powders prepared using the FEAG had submicron sizes at all concentrations of the spray solution used. On the other hand, the cobalt oxide powders prepared using the ultrasonic spray generator had micron sizes even when the spray solution used had a low concentration $(0.05 \mathrm{M})$. In Figs. 3 and 4, the powders prepared using the FEAG had narrower size distribu- tions than those prepared using the ultrasonic spray generator. Assuming that one dense powder is derived from one droplet, the mean size of the powders prepared through spray pyrolysis can be calculated using the following equation:

$$
d_{\text {powder }}=d_{\text {drop }} \times\left(\frac{M_{x} \cdot C \cdot 10^{-3}}{\rho_{x}}\right)^{1 / 3}
$$

where $d_{\text {drop }}$ and $d_{\text {powder }}$ are the mean diameters of the droplets and the powders, respectively; $\rho_{x}$ and $M_{x}$ are the density and molecular weight, respectively, of the oxide or dried salt powders; and $C$ is the molar concentration of the spray solution. Therefore, the mean size and size distribution of the powders were affected by the mean size and size distribution of the droplets that were formed by the spray generator used. The droplets that were formed by the FEAG were finer, and their size distribution was narrower, than those that were formed by the ultrasonic spray generator. ${ }^{17)}$

\section{Conclusion}

The cobalt oxide powders directly prepared through spray pyrolysis had a spherical shape and non-aggregation properties. However, their mean size and size distribution were 
affected by the types of spray generators that were used. The FEAG produced droplets that were finer and that had a narrower size distribution than those produced using an ultrasonic spray generator. It can thus be concluded that the FEAG is the aropriate generator to use for the preparation of cobalt oxide powders with submicron sizes and a spherical shape.

\section{References}

1) E. M. Logothetis, K. Park, A. H. Meitzler and K. R. Laud, Appl. Phys. Lett., 26, 209-211 (1975).

2) H. Kim, D. W. Park, H. C. Woo and J. S. Chung, Appl. Catal. $B, 19,233-243$ (1998).

3) E. Antolini, Mater. Res. Bull., 32, 9-14 (1997).

4) W. Estrada, M. C. A. Fantini, S. C. de Castro, C. N. Polo da Fonseca and A. Gorenstein, J. Appl. Phys., 74, 5835-5841 (1993).

5) Z. W. Zhao, K. Konstantinov, L. Yuan, H. K. Liu and S. X. Dou, J. Nanosci. Nanotechnol., 4, 861-866 (2004).

6) Y. Jiang, Y. Wu, B. Xie, Y. Xie and Y. Qian, Mater. Chem. Phys., 74, 234-237 (2002).

7) G. Furlanetto and L. Formaro, J. Colloid Interf. Sci., 170,
169-175 (1995)

8) Z. Yuan, F. Huang, C. Feng, J. Sun and Y. Zhou, Mater. Chem. Phys., 79, 1-4 (2003).

9) T. Nakamura and A. Kajiyama, Solid State Ionics, 123, 95-101 (1999).

10) H. Yang, Y. Hu, X. Zhang and G. Qiu, Mater. Lett., 58, 387-389 (2004)

11) J. Jiu, Y. Ge, X. Li and L. Nie, Mater. Lett., 54, 260-263 (2002).

12) T. C. Pluym and T. T. Kodas, J. Mater. Res.,10, 1661-1673 (1995).

13) Y. C. Kang, H.S. Roh and S. B. Park, Adv. Mater., 12, 451-453 (2000)

14) G. L. Messing, S. C. Zhang and G. V. Jayanthi, J. Am. Ceram. Soc., 76, 2707-2726 (1993).

15) A. Gurav, T. Kodas, T. Pluym and Y. Xiong, Aerosol Sci. \& Tech., 19, 411-452 (1993).

16) C. S. Zhang, G. L. Messing and W. Huebner, J. Aerosol Sci., 22, 585-599 (1991).

17) Y. C. Kang and S. B. Park, J. Aerosol Sci., 26, 1131-1138 (1995). 